\title{
Revalidation of Mangled Extremity Severity Score in lower limb traumatic vascular injury
}

\author{
H.R.Mosalam, A.A.Salem, A.M.A.El-Samadoni, H.S.Afifi and K.M.Ibrahim \\ General and Vascular SurgeryDept., Faculty of Medicine, Benha Univ., Benha, Egypt \\ E-Mail: Kariem_ibrahim@fmed.bu.edu.eg
}

\begin{abstract}
Extreme horrendous lower appendages wounds have been related with high rate of different frameworks included. That is settle on trouble and weight on specialist's dynamic either to sever or protect the harmed appendages. the evaluation of seriousness of injury to the appendage is generally done dependent on abstract rules as opposed to target rules. The error of this strategy drove a few creators to endeavor to measure the seriousness of injury and to propose scores in order to build up mathematical rules.The Mangled Extremity Severity Score (MESS) is presumably the most widely recognized scoring framework utilized. Point revalidation of Mangled Extremity Severity Score (MESS) in lower appendage awful vascular injury. Techniques This is an imminent non randomized investigation, led on 33 patients with serious furthest points wounds that met the measures of the Mangled Extremity Severity Scoring (MESS score at or close to edge (score 7 and score 8) taking care of the Emergency Department (ED) at Benha University Hospital. Result this investigation showed that the most regular influenced vessel was popliteal supply route $(54.5 \%)$ trailed by PTA $(24.2 \%)$ at that point ATA and SFA (18.2\% for each) and CFA (3.0\%) This examination showed that 54.5\% showed breaks, $21.2 \%$ showed disengagement, $18.2 \%$ showed nerve injury and $42.4 \%$ showed muscle injury, Mean length of emergency clinic stay was 10 days with standard deviation of 3 days, just $27.3 \%$ of study populace went through 2ry removal. Ends the MESS was not prescient of removal Overall with the need of additional revalidation and the chance of appendage rescue for MESS score over the edge in the present of new period in remaking methods.
\end{abstract}

Keywords: MESS lower limb traumatic vascular.

\section{Introduction}

Serious horrendous lower appendages wounds have been related with high frequency of numerous frameworks included (Integument, nerve, bone, and vascular designs). That is settle on trouble and weight on specialist's dynamic either to sever or save the harmed appendages [1].

During the 1960s, the presence of an extreme squash injury or a vascular physical issue was adequate to warrant a removal. Be that as it may, the advancement of refined microsurgical remaking methods alongside the improvement of present day skeletal obsession and reproduction gadgets during the 1980s made appendage rescue in fact conceivable even in the most extraordinary cases [2].

Open wounds are regular in agricultural nations, where most amputees don't have the admittance to current prosthetic gadgets. Consequently, there is a requirement for evenhanded and dependable techniques for evaluating a seriously harmed appendage and for foreseeing a decent result [3]. However, the evaluation of seriousness of injury to the appendage is normally done dependent on emotional standards instead of target rules. The paradox of this strategy drove a few creators to endeavor to measure the seriousness of injury and to propose scores to set up mathematical rules $[4,5]$.The engineers of these scoring frameworks endeavored to approve them by showing high paces of explicitness and affectability in anticipating appendage rescue [6,7] an ideal score should satisfy a couple of fundamental measures before it tends to be acknowledged as a clinical rule. The score should perform reliably and with a serious level of affectability and particularity If it must be functional and helpful, it should be basic and promptly relevant in the working room

In a perfect world, an appendage rescue score ought to be $100 \%$ delicate (all cut away appendages will have injury appendage rescue scores at or over the limit) and $100 \%$ explicit (all rescued appendages will have scores underneath the edge). Notwithstanding, this degree of exactness is incomprehensible in any clinical setting, particularly in an open injury, where the factors affecting the result are frequently hard to mathematically measure and not limited to the situation with the appendage or the even the person $[9,10]$. There are significant outer factors, for example, the specialized offices accessible and the careful abilities of the treating group. Thus, it is more pragmatic to search for the most elevated conceivable pace of affectability and explicitness as opposed to a $100 \%$ amazing precision [11].

A high pace of particularity is more significant with the goal that we can altogether decrease the event of salvageable appendages being erroneously allocated to a score over the choice limit and being superfluously removed. Be that as it may, affectability is additionally significant in order to evade improper endeavors at rescue with its related high dismalness and even mortality [12].

Over the long run, trying to measure the seriousness of injuries and to set up rules for dynamic, regardless of whether to save or to cut away the ruined furthest point, a few scoring frameworks have been created. Most consolidate bone cracks, delicate tissue harm, vascular, nerve and ligament injuries.

The Mangled Extremity Severity Score (MESS) is likely the most well-known scoring framework utilized, trailed by the Predictive Salvage Index (PSI), Limb 
Salvage Index (LSI), Mangled Extremity Syndrome Index (MESI), Nerve injury, ischemia, delicate tissue, skeletal injury, stun, period of patient score (NISSSA), and the Hannover Fracture Scale [13].

Most limit injury scoring frameworks were created more than 15 years back. Muscular, plastic, and vascular medical procedure methods and techniques have changed significantly from that point forward. That has had an effect as far as appendage rescue, just as auxiliary recreation [14].

\section{Patients and methods}

This is an imminent non randomized examination that was directed on 33 patients taking care of the crisis office at Benha college clinic with cut off lower appendage horrendous vascular injury all patients met the measures of mutilated limit score Data was gathered in pre-coordinated information sheet by the analyst from patients satisfying incorporation and prohibition rules.
All patients were clinically surveyed and overseen utilizing the ABCDE convention Also, by utilizing the Mangled Extremity Severity Score (MESS) [Skeletal/delicate tissue injury-Limb ischemia-ShockAge) to assess the prognostic foreseeing variables of the result of awful furthest points patients

The patients were followed up and recorded till one of the accompanying results is reached.

A. Patients with MESS score below threshold (<7) This group received further treatment

B. Patients with MESS score at or above nine $(\geq 9)$ This group underwent immediate amputation

C. Both of the above mentioned group was not subjected to our study.

D. Patients with MESS score at or near threshold (score 7 and score 8)

Underwent attempt limb salvage and followed up carefully postoperative.
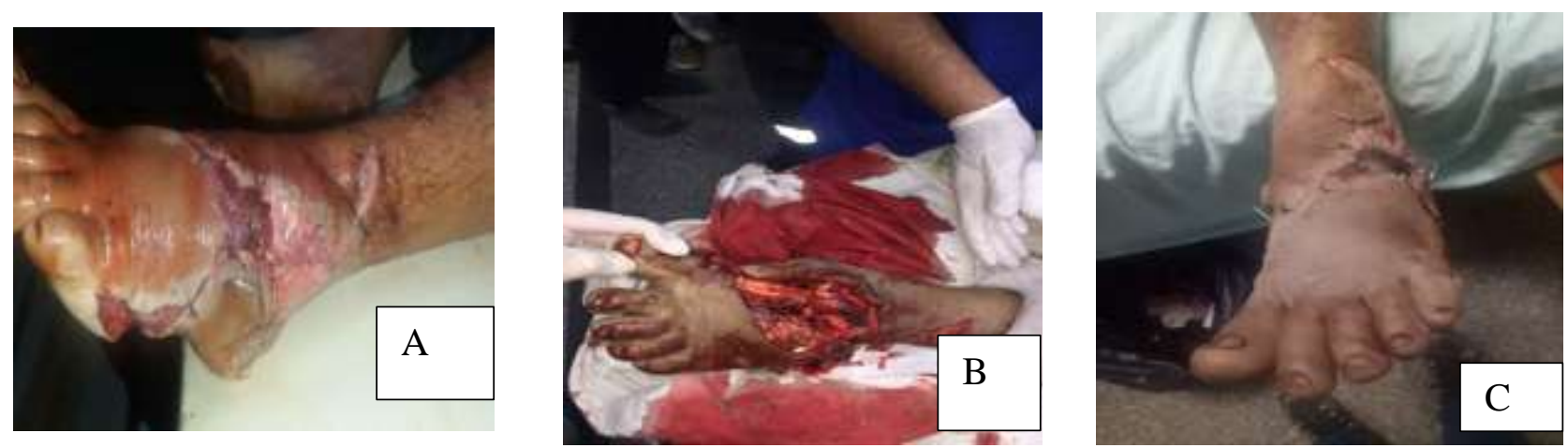

Fig (1) A. Post traumatic crushed LT lower limb with injury of both ATA and PTA of arterial injury.

C. 2 weeks post-operative.

\section{Result}

This study was done in surgery department, Benha university hospital, on33 patients with lower limb traumatic vascular injury \& MESS score of 7 to 8 .

In this study the Mean age was 36 years with standard deviation of 13 years. As regard gender, 63.6\% were males while $36.4 \%$ were females
The most frequent mechanism of trauma was RTA $(57.6 \%)$ followed by shotgun and stab wound $(9.1 \%$ for each). The least frequent mechanism was falling from height \& simple fracture (3.0\% for each).

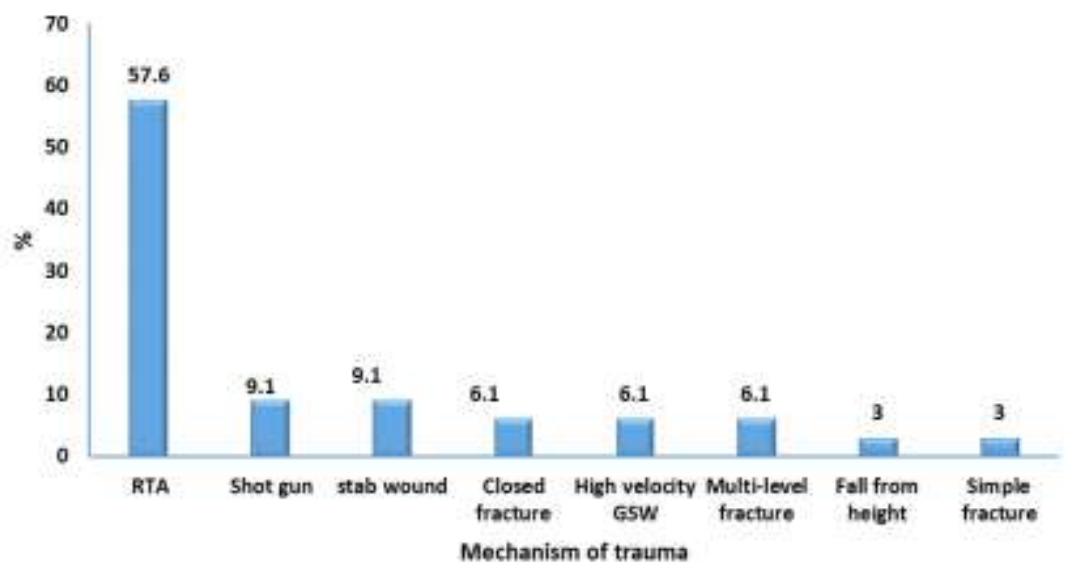

Fig (2) Mechanism of trauma of study population. 
The most frequent method of diagnosis was CT angio (45.5\%) followed by doppler US and surgical exploration (27.3\% for each)

The most frequent affected vessel was popliteal artery $(54.5 \%)$ followed by PTA $(24.2 \%)$ then SFA (18.2\%), ATA \& SFA (18.2\% for each) and CFA (3.0\%)
The most frequent mechanism was thrombosis $(51.5 \%)$ followed by contusion $(18.1 \%)$ then complete transection \& multiple perforations ( $15.2 \%$ for each).

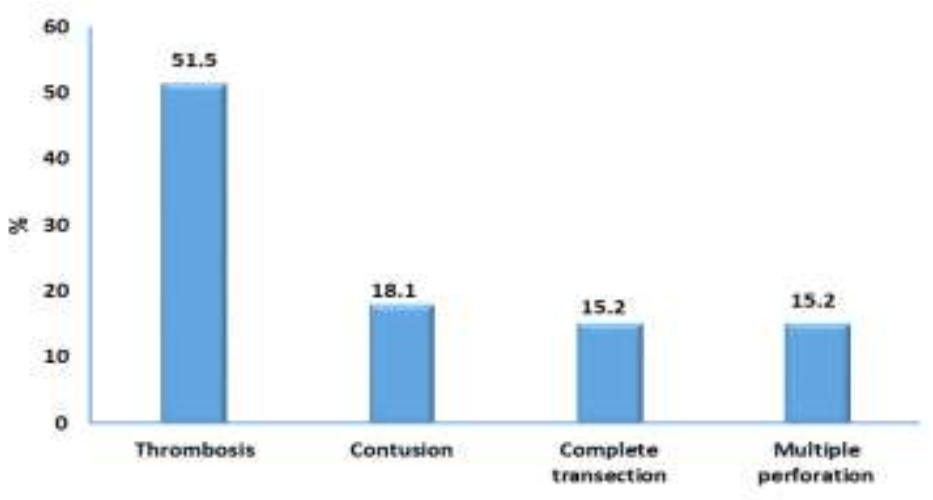

Fig (3) Mechanism of vascular injury in study population.

The most frequent reconstruction technique was autologous venous bypass $(48.5 \%)$ followed by Excision and direct anastomosis (21.2\%) then Direct anastomosis $(15.2 \%)$, reversed saphenous graft $(9.1 \%)$ and Saphenous graft and direct anastomosis $(6.1 \%), 54.5 \%$ showed fractures, $21.2 \%$ showed dislocation, $18.2 \%$ showed nerve injury and $42.4 \%$ showed muscle injury Mean length of hospital stay was 10 days with standard deviation of 3 days. Only $27.3 \%$ of study population underwent 2ry amputation.

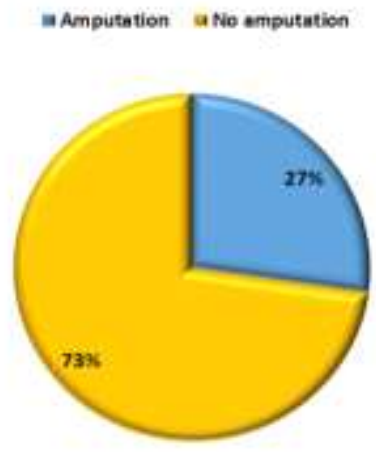

Fig (4) Frequency of 2ry amputation in study population.

\section{Discussion}

Numerous creators have endeavored to evaluate the seriousness of the injury and to set up mathematical rules for the choice to remove or rescue the appendage. These incorporate the MESS, the PSI, the LSI, the nerve injury, ischemia, delicate tissue injury, skeletal injury and age of the patient NISSA) score and the Hanover crack scale97.) [15].

Johansen et al built up the MESS through a review investigation of 25 patients with joined vascular and muscular wounds and recommended that a MESS of 7 be utilized to propel removal [16].

In our enlightening examination a complete 33 patients with Mean age was 36 years and MESS around limit (7 and 8 ) just 9 patients( $27.3 \%$ ) of study populace went through 2ry removal., 24 appendages (72.7\%) rescued had great capacity.

The aftereffect of this investigation is in concurrence with past examination by Lin. In his review concentrate on patients with 36 disfigured lower furthest points with Gustilo Type III C. Results propose that numerous appendages with MESS score of equivalent to or more than 7 might be rescued [17].

All the more as of late, Brown et al assessed the prescient precision Of the MESS among a bigger partner (86 appendages) with ballistic Lower furthest point wounds supported in Iraq and Afghanistan The creators found the MESS to have a positive prescient Value of $64.3 \%$ and an affectability and explicitness of $85.7 \%$ and $84.4 \%$ separately [18]. 
In light of these outcomes, the creators inferred that the MESS was not prescient of removal Overall; these outcomes affirm that in the setting of high Energy, battle related lower limit injury, the MESS is Ineffective in anticipating the requirement for removal at the purpose of injury.

\section{Conclusion}

The target of this examination was to investigate and discover the clinical utility of Mangled furthest point seriousness score (MESS) in seriously harmed lower appendages.

Based on this spellbinding examination it very well may be reasoned that Mangled limit seriousness score is a practical, moderately straightforward and promptly accessible scoring framework, which helps the specialist to recognize factors that may eventually impact the result of a seriously damaged furthest point with blood vessel bargain, however the MESS was not prescient of removal Overall.

\section{References}

[1] L.Fodor, R.Sobec, L.Sita-Alb, M.Fodor, C.Ciuce. Mangled lower extremity: can we trust the amputation scores? Int J Burn Trauma, Vol.2(1), PP.51-8,2012.

[2] S.T.Hansen. Jr The type-IIIc tibial fracture: Salvage or amputation. J Bone Joint Surg Am, Vol.69, PP.799-800,1987.

[3] M.J.Bosse, E.J.MacKenzie, J.F.Kellam, A.R.Burgess, L.X.Webb, M.F.Swiontkowski.An analysis of outcomes of reconstruction or amputation of leg-threatening injuries. $\mathrm{N}$ Engl $\mathrm{J}$ Med, Vol.347, PP.1924-31,2002.

[4] S.Rajasekaran, J.Naresh Babu, J.Dheenadayalan, A.P.Shetty, S.R.Sundarajan, M.Kumar.A score for predicting salvage and outcome in Gustilo type-IIIA and type-IIIB open tibial fractures. J Bone Joint Surg Br, Vol.88, PP.1351-60,2006.

[5] M.G.McNamara, J.D.Heckman, E.G.Corley. Severe open fracture of the lower extremity: a retrospective evaluation of the Mangled Extremity Severity Score. J Orthop Trauma, Vol.8, PP.81-7,1994.

[6] F.Bonanni, M.Rhodes, J.F.Lucke. The futility of predictive scoring of mangled lower extremities. J Trauma, Vol.34, PP.99-104,1993.

[7] R.H.Lange. Limb reconstruction versus amputation decision making in massive lower extremity trauma. Clin Orthop, Vol.243, PP.92-9,1989.
[8] S.P.Baker, B.O'Neill, W.Haddon, W.B.Long. The injury severity score: A method for describing patients with multiple injuries and evaluating emergency care. J Trauma, Vol.14, PP.187-96,1974.

[9] R.M.Durham, B.M.Mistry, J.E.Mazuski, M.Shapiro, D.Jacobs. Outcome and utility of scoring systems in the management of the mangled extremity. Am J Surg, Vol.172, PP.569-74,1996.

[10] R.J.Brumback, A.L.Jones. Interobserver agreement in the classification of open fractures of the tibia: The results of a survey of two hundred and fortyfive orthopaedic surgeons. J Bone Joint Surg Am, Vol.76, PP.1162-6,1994.

[11]L.X.Webb, M.J.Bosse, R.C.Castillo, E.J.MacKenzie. LEAP Study Group Analysis of surgeon-controlled variables in the treatment of limb-threatening typeIII open tibial diaphyseal fractures. J Bone Joint Surg Am, Vol.89, PP.923-8,2007.

[12] E.J.MacKenzie, A.S.Jones, M.J.Bosse, R.C.Castillo, A.N.Pollak, L.X.Webb. Health-care costs associated with amputation or reconstruction of a limbthreatening injury. J Bone Joint Surg Am, Vol.89, PP.1685-92,2007.

[13]C.Krettek, A.Seekamp, H.Kontopp, H.Tscherne. Hannover Fracture Scale '98-re-evaluation and new perspectives of an established extremity salvage score. Injury, Vol.32, PP. 317-328,2001.

[14]P.Mommsen, C.Zeckey, F.Hildebrand, M.Frink, N.Khaladj, N.Lange, C.Krettek, C. Probst .Traumatic extremity arterial injury: epidemiology, diagnostics, treatment and prognostic value of Mangled Extremity Severity Score. J OrthopSurg Res, Vol.5, PP. 25,2010.

[15]M.K.Pimple, M.M.Desai, Hirak. in mangled extremities. Indian J Orthop,2009.

[16] K.Johansen, M.Daines, T.Howey. Objective criteria accurately predictamputation following lower extremity trauma. J Trauma, Vol.30, PP.568573,1990.

[17] C.h.Lin, F.C.Wei, L.S.Levin, J.i.Su, W.L.Yeh. The functional outcome of lower extremity fractures with vascular injury. J Trauma, Vol.43, PP.480-5,1997.

[18] K.V.Brown, A.Ramasamy, J.McLeod. Predicting the need for early amputation in ballistic mangled extremity injuries. J Trauma, Vol.66, PP.S93-S98, 2009. 